\title{
PENGARUH TEKANAN ANGGARAN WAKTU, PROSEDUR REVIEW, KONTROL KUALITAS DAN KARAKTERISTIK PERSONAL AUDITOR TERHADAP PERILAKU PENGURANGAN KUALITAS AUDIT (STUDI EMPIRIS PADA KANTOR AKUNTAN PUBLIK DI YOGYAKARTA DAN SOLO)
}

\author{
Astri Pramudianti \\ Prodi Akuntansi Universitas Negeri Yogyakarta \\ apramudianti@gmail.com \\ Ngadirin Setiawan \\ Staf Pengajar Jurusan Akuntansi Universitas Negeri Yogyakarta
}

\begin{abstract}
Abstrak : Pengaruh Tekanan Anggaran Waktu, Prosedur Review, Kontrol Kualitas Dan Karakteristik Personal Auditor Terhadap Perilaku Pengurangan Kualitas Audit (Studi Empiris Pada Kantor Akuntan Publik Di Yogyakarta Dan Solo. Penelitian ini bertujuan untuk mengetahui pengaruh : (1) Tekanan Anggaran Waktu terhadap Perilaku Pengurangan Kualitas Audit, (2) Prosedur Review terhadap Perilaku Pengurangan Kualitas Audit, (3) Kontrol Kualitas terhadap Perilaku Pengurangan Kualitas Audit, (4) Karakteristik Personal Auditor terhadap Perilaku Pengurangan Kualitas Audit (5) Tekanan Anggaran Waktu, Prosedur Review, Kontrol Kualitas dan Karakteristik Personal Auditor terhadap Perilaku Pengurangan Kualitas Audit. Populasi sebanyak 120. Sampel sebanyak 45. Data diperoleh menggunakan kuesioner. Teknik pengambilan sampel menggunakan random sampling. Hasil penelitian menunjukkan bahwa (1) Tekanan Anggaran Waktu berpengaruh positif dan signifikan terhadap Perilaku Pengurangan Kualitas Audit (2) Prosedur Review berpengaruh negatif dan signifikan terhadap Perilaku Pengurangan Kualitas Audit. (3) Kontrol Kualitas berpengaruh negatif dan signifikan terhadap Perilaku Pengurangan Kualitas Audit. (4) Karakteristik Personal Auditor berpengaruh negatif dan signifikan terhadap Perilaku Pengurangan Kualitas Audit. (5) Terdapat Pengaruh signifikan antara Tekanan Anggaran Waktu, Prosedur Review, Kontrol Kualitas dan Karakteristik Personal Auditor terhadap Perilaku Pengurangan Kualitas Audit.
\end{abstract}

Kata Kunci: Perilaku Pengurangan Kualitas Audit, Tekanan Anggaran Waktu, Prosedur Review, Kontrol Kualitas, Karakteristik Personal Auditor.

Abstract : The Effect Of Time Budget Pressure, Review Procedure, Quality Control And Auditor Personal Characteristics On Reduce Audit Quality Behavior (Empirical Studies At Public Auditing Firm In Yogyakarta And Solo).

The purpose of this study was to determine the effect of : (1) Time Budget Pressure on Reduce Audit Quality Behavior, (2) Review Procedure on Reduce Audit Quality Behavior, (3) Quality Control on Reduce Audit Quality Behavior, (4) Auditor Personal Characteristics on Reduce Audit Quality Behavior,(5)Time Budget Pressure, Review Procedure, Quality Control And Auditor Personal Characteristics on Reduce Audit Quality Behavior. This research took sample of 45 respondents. Data collection techniques used a questionnaire. The sampling technique used random sampling. The result showed that : (1) Time Budget Pressure has positive and significant effect on Reduced Audit Quality Behavior. (2) Review Procedure has negatif and significant effect on Reduced Audit Quality Behavior. (3) Quality Control has negatif and significant effect on Reduced Audit Quality Behavior. (4) Auditor Personal Charateristics has negatif and significant effect on Reduced Audit Quality Behavior. (5) Time Budget Pressure, Review Procedure, Quality Control and Auditor Personal Characteristic has significant effect on Reduced Audit Quality Behavior.

Keywords : Reduced Audit Quality Behavior, Time Budget Pressure, Review Procedure, Quality Control and Auditor Personal Characteristics. 


\section{JURNAL NOMINAL / VOLUME V NOMOR 2 / TAHUN 2016}

\section{PENDAHULUAN}

Laporan keuangan memiliki peranan yang penting. Baik bagi perusahaan sebagai pihak internal maupun bagi pihak eksternal seperti kreditor, pemerintah dan investor. Tidak dapat dipungkiri, pada kenyataannya terdapat perbedaan penguasaan informasi antara pihak internal perusahaan dengan pihak eksternal. Perbedaan penguasaan informasi inilah yang membuat jasa audit eksternal menjadi sangat penting untuk menjamin keandalan laporan keuangan yang disusun oleh pihak manajemen perusahaan dengan melakukan proses audit terhadap laporan keuangan perusahaan. Oleh karena fungsinya yang penting, maka auditor dituntut untuk menghasilkan laporan audit yang berkualitas.

Kualitas audit merupakan masalah yang penting. Audit yang tidak berkualitas dapat menyebabkan pengguna laporan audit salah dalam pengambilan keputusan. Selain itu, kepercayaan para pemakai laporan keuangan terhadap profesi auditor sangat bergantung pada kualitas laporan audit yang dihasilkan KAP. Meskipun demikian, beberapa kasus kecurangan yang mulai berkembang pada tahun 2000 membuktikan bahwa tidak semua laporan audit yang dihasilkan berkualitas.

Salah satu penyebab rendahnya kualitas audit yang dihasilkan adalah perilaku disfungsional yang dilakukan auditor. Perilaku disfungsional auditor diartikan sebagai perilaku - perilaku yang dilakukan auditor yang dapat mengakibatkan kualitas audit menurun baik secara langsung maupun tidak langsung (Kelley dan Margheim, 1990). Perilaku disfungsional yang berdampak langsung terhadap kualitas audit disebut dengan Perilaku Pengurangan Kualitas Audit (Reduced Audit Quality Behavior). Perilaku Pengurangan Kualitas Audit diartikan sebagai perilaku auditor yang dengan sengaja mereduksi keefektifan bukti audit yang dikumpulkan.

Ada beberapa hal yang dapat menyebabkan auditor melakukan Perilaku Pengurangan Kualitas Audit diantaranya adalah faktor eksternal (tekanan,, sistem pengendalian dan gaya pengendalian) dan faktor internal (Karakteristik Personal Auditor dan Sifat Kepribadian).

Untuk meningkatan efisiensi kinerja auditor, KAP sering memberlakukan anggaran waktu. Namun sayangnya, pada kebanyakan KAP anggaran waktu yang diberikan tidak sesuai dengan jumlah pekerjaan yang harus dilaksanakan. Kewajiban untuk memenuhi anggaran waktu inilah yang diduga dapat mendorong auditor dalam melakukan Perilaku Pengurangan Kualitas Audit.

Perilaku disfungsional sebenarnya dapat dicegah dengan penerapan sistem pengendalian yang baik. Prosedur Review dan Kontrol Kualitas diduga menjadi salah satu bentuk sistem pengendalian yang dapat 
menurunkan Perilaku Pengurangan Kualitas Audit. Hal ini dikarenakan penerapan Prosedur Review dan Kontrol Kualitas dengan efektif membuat seluruh pekerjaan auditor ditinjau ulang sehingga segala bentuk perilaku disfungsional termasuk Perilaku Pengurangan Kualitas Audit dapat dideteksi.

Selain faktor eksternal, faktor internal dalan diri auditor juga dapat mempengaruhi kecenderungan auditor dalam melakukan Perilaku Pengurangan Kualitas Audit. Salah satu faktor internal yang diduga berpengaruh terhadap kecenderungan auditor dalam melakukan Perilaku Pengurangan Kualitas Audit adalah Karakteristik Personal Auditor. Ada beberapa penelitian sebelumnya yang telah dilakukan berkaitan dengan Perilaku Pengurangan Kualitas Audit. Diantaranya adalah penelitian Malone dan Roberts (1996) yang meneliti hubungan Tekanan Anggaran Waktu dengan Perilaku Pengurangan Kualitas Audit. Hasil penelitian menunjukkan bahwa terdapat hubungan negatif antara Tekanan Anggaran Waktu dengan Perilaku Pengurangan Kualitas Audit. Berbeda dengan penelitian sebelumnya, penelitian Conram (2000) menyatakan bahwa terdapat hubungan positif antara Tekanan Anggaran Waktu dengan Perilaku Pengurangan Kualitas Audit. Adanya perbedaan hasil penelitian dan belum adanya penelitian tentang pengaruh Tekanan Anggaran Waktu, prosedur review, Kontrol Kualitas, dan Karakteristik Personal Auditor terhadap Perilaku Pengurangan Kualitas Audit pada auditor di KAP Yogyakarta dan Solo membuat peneliti tertarik untuk melakukan penelitian dengan judul "Pengaruh Tekanan Anggaran Waktu, Prosedur Review, Kontrol Kualitas dan Karakteristik Personal Auditor Terhadap Perilaku Pengurangan Kualitas Audit pada KAP di Yogyakarta dan Solo"

\section{METODE PENELITIAN}

Jenis Penelitian

Penelitian ini menggunakan pendekatan kuantitatif. Data kuantitatif merupakan data yang berbentuk angka atau data kualitatif yang diangkakan (scoring) (Sugiyono, 2012). Jenis penelitian yang digunakan adalah kausal komparatif yang bertujuan untuk mengetahui ada tidaknya hubungan sebab akibat dari variabel variabel yang diteliti.

\section{Waktu dan Tempat Penelitian}

Penelitian ini dilaksanakan di Kantor Akuntan Publik yang ada di Yogyakarta dan Solo. Waktu pelaksanaan penelitian bulan Januari sampai bulan Mei 2016. 
Definisi Operasional Variabel Penelitian

1. Variabel Dependen (Y)

Perilaku Pengurangan Kualitas Audit adalah perilaku auditor yang dengan sengaja melakukan tindakan - tindakan yang dapat mereduksi kualitas bukti audit yang dikumpulkan sehingga berakibat pada menurunnya kualitas audit yang dihasilkan. Bentuk - bentuk Perilaku Pengurangan Kualitas Audit diantaranya adalah review yang dangkal terhadap dokumen klien, bias dalam pemilihan sampel, tidak memperluas scope pengujian ketika terdeteksi ketidakberesan, tidak meneliti kesesuaian perlakuan akuntansi yang diharapkan klien, penolakan item yang janggal dari sampel, menerima bukti yang meragukan, tidak menguji keseluruhan item yang ada pada sampel, mengurangi jumlah sampel dalam audit, dan tidak memperluas pemeriksaan.

2. Variabel Independen (X)

Tekanan Anggaran Waktu(Time Budget Pressure) merupakan keadaan dimana auditor merasa bahwa jumlah waktu yang dialokasikan oleh KAP kepada personilnya tidak rasional dengan jumlah pekerjaan yang harus dilaksanakan.

Prosedur Review merupakan proses memeriksa ulang hal atau pekerjaan untuk memastikan bahwa semua pekerjaan yang dilaporkan telah diselesaikan auditor benarbenar telah dilaksanakan. Proses ini juga sekaligus untuk memastikan bahwa semua bukti audit yang dibutuhkan telah diikumpulkan.

Kontrol Kualitas adalah prosedur untuk memastikan bahwa prosedur audit yang dilaksanakan telah sesuai dengan standar audit.

Karakteristik Personal Auditor merupakan kualitas dan karakter tertentu yang dimiliki auditor yang akan mempengaruhi perilaku mereka dalam bekerja.

\section{Prosedur Penelitian}

Penelitian ini dilakukan dengan menyebar kuesioner ke auditor yang bekerja di KAP yang ada di Yogyakarta dan Solo. Prosedur penelitian sebagai berikut :

a. Peneliti memilih responden yang akan diteliti yaitu auditor yang bekerja pada Kantor Akuntan Publik di Yogyakarta dan Solo.

b. Sebelum penelitian di laksanakan, peneliti menjelaskan tujuan penelitian kepada responden.

c. Setelah responden mengetahui tujuan penelitian, peneliti memberikan penjelasan mengenai cara - cara pengisian kuesioner.

d. Responden diminta untuk melakukan pengisian pada bagian identitas responden seperti nama, jenis kelamin, pengalaman audit dan lain - lain.

e. Selanjutnya responden diminta untuk mengisi kuesioner dengan memberi tanda silang pada salah satu pilihan jawaban yang meliputi jawaban sangat setuju, 
setuju, tidak setuju dan sangat tidak setuju.

f. Jika terdapat pertanyaan maka responden dapat bertanya kepada peneliti.

\section{Populasi dan Sampel}

Populasi pada penelitian ini adalah semua auditor yang bekerja pada KAP yang ada di wilayah Yogyakarta dan Solo. Pemilihan populasi tersebut dikarenakan belum ada penelitian dengan judul serupa yang dilakukan pada KAP yang ada di Yogyakarta dan Solo. Jumlah auditor yang ada di Yogyakarta dan Solo sebanyak 120 auditor. Sampel sebanyak 45 auditor. Teknik pengambilan sampel menggunakan random sampling yaitu teknik pengambilan sampel dengan cara mengambil langsung dari populasi secara acak / random.

\section{Metode Pengumpulan Data}

Data dikumpulkan dengan menggunakan kuesioner yang dibagikan kepada responden yaitu auditor yang bekerja di KAP di wilayah Yogyakarta dan Solo. Kuesioner akan dibagikan secara langsung kepada responden untuk diisi sesuai dengan petunjuk yang ada dan kemudian dikembalikan kepada peneliti untuk dianalisis lebih lanjut menggunakan metode yang sesuai intuk membuktikan hipotesis yang telah dibuat.

\section{Uji Coba Instrumen}

Data yang digunakan dalam uji coba instrument diambil dari auditor yang bekerja pada KAP yang ada di wilayah Yogyakarta dan Solo. Pengambilan data menggunakan kuesioner dengan skala likert untuk mengukur kecenderungan auditor melakukan Perilaku Perngurangan Kualitas Audit(Y), Tekanan Anggaran Waktu yang dirasakan auditor $\left(\mathrm{X}_{1}\right)$, efektivitas Prosedur Review $\left(\mathrm{X}_{2}\right)$, efektivitas Kontrol Kualitas $\left(\mathrm{X}_{3}\right)$, dan Tingkat Karakteristik Personal Auditor $\left(\mathrm{X}_{4}\right)$. Uji coba instrument menggunakan uji terpakai pada 30 responden.

a. Uji Validitas Data

Uji validitas data dilakukan dengan melihat nilai korelasi bivariate antara masing masing skor indikator dengan total skor konstruk. Pengujian dilakukan dengan menggunakan bantuan program SPSS versi 20 dengan melihat Corrected Item - Total Correlation setiap item instrumen. Pernyataan kuesioner dikatakan valid apabila nilai $\mathrm{r}$ hitung > $\mathrm{r}$ tabel.

b. Uji Reliabilitas Data

Uji reliabilitas data menggunakan pendekatan reliabilitas konsistensi internal. Untuk mengukur konsistensi internal, peneliti menggunakan Cronbach Alpha. Imam Ghozali (2011) menyatakan bahwa suatu variabel atau konstruk dikatakan reliabel apabila memberikan nilai cronbach alpha $\geq 0,600$. Perhitungan dilakukan dengan SPSS 20. 


\section{JURNAL NOMINAL / VOLUME V NOMOR 2 / TAHUN 2016}

\section{Teknik Analisis Data}

a. Analisis Regresi Linear Sederhana

Analisis regresi sederhana didasarkan pada hubungan fungsional ataupun kausal satu variabel independen dengan satu varaibel dependen. Persamaan umum regresi linear sederhana $\hat{Y}=a+b X$. Uji t dilakukan untuk menguji signifikansi konstanta dan variabel bebas dengan satu variabel terikat.

b. Analisis Regresi Linear Berganda

Regresi linear berganda digunakan untuk mengetahui pengaruh Tekanan Anggaran Waktu, prosedur review, Kontrol Kualitas dan Karakteristik Personal Auditor terhadap Perilaku Pengurangan Kualitas Audit di KAP yang ada di Yogyakarta dan Solo. Persamaan umum regresi linear berganda $Y=a+b_{1} X_{1}+b_{2} X_{2}+b_{3} X_{3}+b_{4} X_{4}$. Uji F hitung dimaksudkan untuk menguji model regresi atas pengaruh seluruh variabel $\begin{array}{lllllll}\text { independen yaitu: } & X_{1} & X 2 & X_{3} & X_{4} & \text { secara }\end{array}$ simultan terhadap variabel dependen.

\section{HASIL PENELITIAN}

DAN

\section{PEMBAHASAN}

\section{Statistik Deskriptif}

Responden data dalam penelitian ini berjumlah 45 auditor yang bekerja pada KAP yang ada di Yogyakarta da Solo. Analisis deskriptif yang disajikan dalam penelitian ini meliputi harga rerata Mean (M), Modus (Mo), Median (ME), dan Standar Deviasi (SD).

Tabel. 1 Hasil Analisis Deskriptif

\begin{tabular}{llllll}
\hline Ket & $\mathbf{Y}$ & $\mathbf{X}_{\mathbf{1}}$ & $\mathbf{X}_{\mathbf{2}}$ & $\mathbf{X}_{\mathbf{3}}$ & $\mathbf{X}_{\mathbf{4}}$ \\
\hline Min & 19 & 14 & 9 & 10 & 34 \\
\hline Max & 28 & 21 & 16 & 16 & 52 \\
\hline $\mathbf{M}$ & 23,18 & 17,76 & 12,82 & 12,71 & 45,40 \\
\hline Mo & 23 & 16 & 12 & 13 & 48 \\
\hline Me & 23 & 18 & 13 & 13 & 47 \\
\hline SD & 2,07 & 2,20 & 2,10 & 1,77 & 4,75
\end{tabular}

Sumber : Data primer yang diolah (2016)

\section{Uji Asumsi Klasik}

a. Uji Normalitas

Tabel. 2 Hasil Uji Normalitas Data

\begin{tabular}{cc}
\hline Var & Uji Kolmogorof-Smirnov \\
\hline $\mathbf{Y}$ & 0,392 \\
\hline $\mathbf{X 1}$ & 0,220 \\
\hline $\mathbf{X 2}$ & 0,390 \\
\hline $\mathbf{X 3}$ & 0,527 \\
\hline $\mathbf{X} 4$ & 0,248 \\
\hline
\end{tabular}

Sumber : Data primer yang diolah (2016)

Tabel di atas menunjukkan hasil dari pengolahan data uji normalitas dengan menggunakan SPSS 20. Data di atas menunjukkan nilai uji kolmogorof - smirnof yang lebih besar dari 0,05. Hal ini menunjukkan bahwa model regresi dalam penelitian ini memenuhi asumsi normalitas.

\section{b. Uji Linearitas}

Hasil pengolahan data uji linearitas dengan SPSS versi 20 adalah :

Tabel. 3 Hasil Uji Linearitas

\begin{tabular}{ccl}
\hline \multicolumn{1}{c}{ Variabel } & Sig & \multicolumn{1}{c}{ Keterangan } \\
\hline X1 dengan Y & 0,323 & Linear \\
\hline X2 dengan Y & 0,839 & Linear \\
\hline X3 dengan Y & 0,247 & Linear \\
\hline X4 dengan Y & 0,799 & Linear \\
\hline
\end{tabular}

Sumber : Data primer yang diolah (2016)

Berdasarkan tabel di atas diketahui bahwa nilai signifikansi hubungan antara variable $\mathrm{X}$ dengan $\mathrm{Y}$ menunjukkan nilai lebih besar dari 0,05 sehingga dapat disimpulkan bahwa model regresi dalam penelitian ini berbentuk linear. 


\section{c. Uji Multikolinearitas}

Tabel. 4 Hasil Uji Multikolinearitas

\begin{tabular}{ccc}
\hline Var & Tolerance & VIF \\
\hline $\mathbf{X}_{\mathbf{1}}$ & 0,853 & 1,172 \\
\hline $\mathbf{X}_{\mathbf{2}}$ & 0,536 & 1,865 \\
\hline $\mathbf{X}_{\mathbf{3}}$ & 0,847 & 1,181 \\
\hline $\mathbf{X}_{\mathbf{4}}$ & 0,603 & 1,659 \\
\hline
\end{tabular}

Sumber : Data primer yang diolah (2016)

Dari tabel tersebut dapat disimpulkan bahwa tidak terjadi multikolineritas pada model regresi dikarenakan nilai VIF $<10$ dan nilai Tolerance $>0,1$.

\section{d. Uji Heteroskedastisitas}

Tabel. 5 Hasil Uji Heteroskedastisitas

\begin{tabular}{cc}
\hline Variabel & Sig \\
\hline $\mathbf{X}_{\mathbf{1}}$ & 0,167 \\
\hline $\mathbf{X}_{\mathbf{2}}$ & 0,699 \\
\hline $\mathbf{X}_{\mathbf{3}}$ & 0,779 \\
\hline $\mathbf{X}_{\mathbf{4}}$ & 0,176 \\
\hline
\end{tabular}

Sumber : Data primer yang diolah (2016)

Dari tabel di atas dapat dismpulkan bahwa tidak terjadi heteroskedastisitas pada model regresi dikarenakan nilai signifikansi $>0,05$. Sehingga model regresi layak dipakai.

\section{Uji Hipotesis}

Dalam penelitian ini, uji hipotesis dilakukan dengan analisis regresi linear sederhana dan analisis regresi linear berganda. Berikut hasil uji hipotesis dengan SPSS 20:

Tabel. 6 Hasil Uji Hipotesis

\begin{tabular}{lcccc}
\hline & Konstanta & Koefisien & Sig & Ket \\
\hline $\mathbf{H}_{1}$ & 13,819 & 0,527 & 0,000 & Sig \\
\hline $\mathbf{H}_{2}$ & 30,530 & $-0,573$ & 0,000 & Sig \\
\hline $\mathbf{H}_{3}$ & 29,905 & $-0,529$ & 0,002 & Sig \\
\hline $\mathbf{H}_{\mathbf{4}}$ & 36,330 & $-0,290$ & 0,000 & Sig \\
\hline $\mathbf{H}_{5}$ & 32,268 & 0,308 & 0,000 & Sig \\
& & $-0,075$ & & \\
& & $-0,319$ & & \\
& & $-0,210$ & & \\
\hline
\end{tabular}

Sumber : Data primer yang diolah (2016)

Berdasarkan tabel di atas dapat dilihat bahwa: $\mathrm{H}_{1}$ diterima dengan nilai koefisien sebesar $0,527, \mathrm{H}_{2}$ diterima dengan nilai koefisien $-0,573, \mathrm{H}_{3}$ diterima dengan nilai koefisien -0,529, $\mathrm{H}_{4}$ diterima dengan nilai koefisien -0,290 dan $\mathrm{H}_{5}$ diterima dengan nilai koefisien 0,308, -0,075, -0,319, dan -0,210.

\section{PEMBAHASAN}

\section{a. Pengaruh Tekanan Anggaran Waktu} terhadap Perilaku Pengurangan

\section{Kualitas Audit}

Hasil penelitian ini mendukung hipotesis pertama yang menyatakan bahwa Tekanan Anggaran Waktu bepengaruh positif dan signifikan terhadap Perilaku Pengurangan Kualitas Audit. Nilai koefisien regresi sebesar 0,527 dengan arah positif. Koefisien korelasi sebanyak 0,562 dan koefisien determinasi sebesar 0,316 menunjukkan Tekanan Anggaran Waktu berpengaruh terhadap Perilaku Pengurangan Kualitas Audit sebesar 31,6\%. Hasil penelitian ini mendukung hasil penelitian Gundry (2006) yang menyatakan bahwa Tekanan Anggaran Waktu berpengaruh positif terhadap Perilaku Pengurangan Kualitas Audit.

Auditor yang merasakan Tekanan Anggaran Waktu yang ketat akan memiliki kecenderungan yang lebih tinggi dalam melakukan Perilaku Pengurangan Kualitas Audit. Adanya kewajiban untuk memenuhi anggaran waktu sedangkan anggaran waktu 


\section{JURNAL NOMINAL / VOLUME V NOMOR 2 / TAHUN 2016}

yang diberikan tidak sesuai dengan jumlah pekerjaan akan mendorong auditor melakukan Perilaku Pengurangan Kualitas Audit. semakin tinggi Tekanan Anggaran Waktu semakin tinggi pula Perilaku Pengurangan Kualitas Audit yang dilakukan.

\section{b. Pengaruh Prosedur Review terhadap} Perilaku Pengurangan Kualitas Audit

Hasil penelitian ini mendukung hipotesis kedua yang menyatakan bahwa Prosedur Review bepengaruh negatif dan signifikan terhadap Perilaku Pengurangan Kualitas Audit. Nilai koefisien regresi sebesar -0,573 dengan arah negatif. Koefisien korelasi sebanyak 0,582 dan koefisien determinasi sebesar 0,339 menunjukkan Prosedur Review berpengaruh terhadap Perilaku Pengurangan Kualitas Audit sebesar $33,9 \%$. Hasil penelitian ini mendukung hasil penelitian Haryanto (2015) yang menyatakan bahwa Prosedur Review berpengaruh negatif terhadap Perilaku Pengurangan Kualitas Audit.

Auditor yang bekerja pada KAP dengan Prosedur Review yang efektif akan memiliki kecenderungan yang lebih rendah dalam melakukan Perilaku Pengurangan Kualitas Audit. Hal ini dikarenakan semua tugas yang dikerjakan auditor akan ditinjau ulang untuk memastikan semua pekerjaan telah dilaksanakan, sehingga risiko terdeteksinya Perilaku Pengurangan Kualitas Audit lebih tinggi. Semakin efektif Prosedur
Review yang diterapkan, semakin rendah Perilaku Pengurangan Kualitas Audit.

\section{c. Pengaruh Kontrol Kualitas terhadap} Perilaku Pengurangan Kualitas Audit

Hasil penelitian ini mendukung hipotesis ketiga yang menyatakan bahwa Kontrol Kualitas bepengaruh negatif dan signifikan terhadap Perilaku Pengurangan Kualitas Audit. Nilai koefisien regresi sebesar -0,529 dengan arah negatif. Koefisien korelasi sebanyak 0,455 dan koefisien determinasi sebesar 0,207 menunjukkan Kontrol Kualitas berpengaruh terhadap Perilaku Pengurangan Kualitas Audit sebesar 20,7\%. Hasil penelitian ini mendukung hasil penelitian Weningtyas (2006) yang menyatakan bahwa Kontrol Kualitas berpengaruh negatif terhadap Perilaku Pengurangan Kualitas Audit.

Auditor yang bekerja pada KAP dengan Kontrol Kualitas yang efektif akan memiliki kecenderungan yang lebih rendah dalam melakukan Perilaku Pengurangan Kualitas Audit. Hal ini dikarenakan prosedur audit yang dilaksanakan akan diawasi untuk memastikan bahwa seluruh prosedur telah sesuai dengan prinsip audit. Hal ini akan membuat risiko terdeteksinya Perilaku Pengurangan Kualitas Audit semakin tinggi. Semakin efektif Kontrol Kualitas yang diterapkan, semakin rendah Perilaku Pengurangan Kualitas Audit. 


\section{d. Pengaruh Karakteristik Personal Auditor Terhadap Perilaku Pengurangan Kualitas Audit}

Hasil penelitian ini mendukung hipotesis keempat yang menyatakan bahwa Karakteristik Personal Auditor bepengaruh negatif dan signifikan terhadap Perilaku Pengurangan Kualitas Audit. Nilai koefisien regresi sebesar $-0,290$ dengan arah negatif. Koefisien korelasi sebanyak 0665 dan koefisien determinasi sebesar 0,443 menunjukkan Karakteristik Personal Auditor berpengaruh terhadap Perilaku Pengurangan Kualitas Audit Sebesar 44,3\%. Hasil penelitian ini mendukung hasil penelitian Widyowati (2013) yang menyatakan bahwa Karakteristik Personal Auditor berpengaruh negatif terhadap Perilaku Pengurangan Kualitas Audit.

Auditor dengan karakteristik personal yang baik akan memiliki kualitas individu yang lebih baik sehingga akan memiliki kecenderungan yang lebih rendah dalam melakukan Perilaku Pengurangan Kualitas Audit yang lebih rendah. Semakin tinggi Karakteristik Personal yang dimiliki auditor, semakin rendah Perilaku Pengurangan Kualitas Audit.

\section{e. Pengaruh Tekanan Anggaran Waktu,} Prosedur Review, Kontrol Kualitas dan Karakteristik Personal Auditor terhadap Perilaku Pengurangan Kualitas Audit

Hasil penelitian ini mendukung hipotesis kelima yang menyatakan bahwa Tekanan Anggaran Waktu, Prosedur Review, Kontrol Kualitas dan Karakteristik Personal Auditor secara bersama - sama berpengaruh signifikan terhadap Perilaku Pengurangan Kualitas Audit. Hal tersebut dibuktikan dengan nilai $\mathrm{F}$ hitung $>\mathrm{F}$ tabel $(20,802>2,61)$. Nilai koefisien regresi sebesar 0,308,-0,075,-0,319, dan -0,210. Koefisien korelasi sebanyak 0,822, koefisien determinasi sebesar 0,675 dan nilai signifikansi sebesar 0,000 menunjukkan bahwa Tekanan Anggaran Waktu, Prosedur Review, Kontrol Kualitas dan Karakteristik Personal Auditor secara bersama - sama berpengaruh signifikan terhadap Perilaku Pengurangan Kualitas Audit. Hasil penelitian ini mendukung hasil penelitian Malone dan Roberts (1996) yang menyatakan bahwa terdapat pengaruh signifikan antara Tekanan Anggaran Waktu, Prosedur Review, Kontrol Kualitas dan Karakteristik Personal Auditor.

Faktor eksternal berupa Tekanan Anggaran Waktu, Prosedur Review dan Kontrol Kualitas berpengaruh signifikan terhadap Perilaku Pengurangan Kualitas Audit. Selain itu, faktor internal berupa Karakteristik Personal Auditor juga berpengaruh secara 


\section{JURNAL NOMINAL / VOLUME V NOMOR 2 / TAHUN 2016}

signifikan terhadap Perilaku Pengurangan Kualitas Audit.

\section{SIMPULAN DAN SARAN}

\section{Simpulan}

Berdasarkan hasil pengujian dan pembahasan, dapat ditarik kesimpulan sebagai berikut :

a. Tekanan Anggaran Waktu berpengaruh positif dan signifikan terhadap Perilaku Pengurangan Kualitas Audit yang ditunjukkan dengan nilai koefisien korelasi (r) sebesar 0,562, koefisien determinasi $\left(r^{2}\right)$ sebesar 0,316 dan nilai signifikansi yang lebih kecil dari Level of Significant $(0,000<0,05)$. Semakin tinggi Tekanan Anggaran Waktu, semakin tinggi pula kecenderungan auditor dalam melakukan Perilaku Pengurangan Kualitas Audit.

b. Prosedur Review berpengaruh negatif dan signifikan terhadap Perilaku Pengurangan Kualitas Audit yang ditunjukkan dengan nilai koefisien korelasi (r) sebesar 0,582, koefisien determinasi $\left(\mathrm{r}^{2}\right)$ sebesar 0,339 dan nilai signifikansi yang lebih kecil dari Level of Significant $(0,000<0,05)$. Semakin efektif Prosedur Review semakin rendah kecenderungan auditor dalam melakukan Perilaku Pengurangan Kualitas Audit. c. Kontrol Kualitas berpengaruh negatif dan signifikan terhadap Perilaku Pengurangan Kualitas Audit yang ditunjukkan dengan nilai koefisien korelasi (r) sebesar 0,455, koefisien determinasi $\left(\mathrm{r}^{2}\right)$ sebesar 0,207 dan nilai signifikansi yang lebih kecil dari Level of Significant $(0,000<0,05)$. Semakin efektif Kontrol Kualitas semakin rendah kecenderungan auditor dalam melakukan Perilaku Pengurangan Kualitas Audit.

d. Karakteristik Personal Auditor berpengaruh negatif dan signifikan terhadap Perilaku Pengurangan Kualitas Audit yang ditunjukkan dengan nilai koefisien korelasi (r) 0,665 , koefisien determinasi $\left(\mathrm{r}^{2}\right)$ 0,443 dan Level of Significant ( $0,000<0,05)$. Semakin tinggi Karakteristik Personal Auditor semakin rendah kecenderungan auditor dalam melakukan Perilaku Pengurangan Kualitas Audit. Karakteristik Personal Auditor secara bersama - sama berpengaruh signifikan terhadap Perilaku Pengurangan Kualitas Audit yang ditunjukkan dengan nilai koefisien korelasi (r) 0,882, koefisien determinasi $\left(\mathrm{r}^{2}\right) 0,675$, nilai $\mathrm{F}$ hitung $>\mathrm{F}$ tabel $(20,802>2,61)$ dan signifikansi $(0,000<0,05) . \quad$ Yang artinya keempat variabel tersebut 


\section{JURNAL NOMINAL / VOLUME V NOMOR 2 / TAHUN 2016}

berpengaruh signifikan terhadap

Perilaku Pengurangan Kualias Audit.

\section{Saran}

Saran yang dapat diberikan sehubungan dengan hasil penelitian dan keterbatasan penelitian adalah sebagai berikut :

a. Bagi Kantor Akuntan Publik

1. KAP perlu menyusun anggaran waktu yang rasional dengan jumlah pekerjaan .

2. KAP perlu menerapkan Prosedur Review dan Kontrol Kualitas yang efektif.

3. KAP perlu mempertimbangkan Karakteristik Personal Auditor dalam rekrutmen auditor untuk memastikan auditor memiliki karakteristik personal yang baik.

b. Bagi Peneliti Selanjutnya

1. Peneliti selanjutnya diharap untuk memperbanyak sampel penelitian dan jenis responden dengan memperluas daerah penelitian dan memilih waktu penelitian yang tepat.

2. Peneliti selanjutnya diharap dapat meneliti KAP dengan pemberian anggaran waktu Botom - Up untuk memperluas hasil penelitian.

3. Peneliti selanjutnya dapat menambahkan pertanyaan negatif untuk menghindari social desirability bias.

\section{DAFTAR PUSTAKA}

Adanan, Silaban. 2009. Perilaku Disfungsional Auditor Dalam Pelaksanaan Program Audit. Disertasi : Universitas Diponegoro Semarang.

Arens, Alvin A., Randal J. Elder, dan Mark S. Beasly. 2008. Auditing dan Jasa Assurance. Jakarta: Erlangga.

Arfan Ikhsan . 2008. Metode Penelitian Akuntansi Keperilakuan. Yogyakarta:Graha Ilmu.

Ayu Puji, Lestari. 2010. Faktor-faktor yang Mempengaruhi Perilaku Auditor dalam

Pengehentian Prematur Prosedur Audit. Skripsi. Semarang : Universitas Diponegoro.

Coram, P., Ng, J., and Woodliff, D. 2003. A Survey of Time Budget Pressure and Reduced Audit Quality among Australian Auditors. Australian Accounting Review 13 (1).

DeAngelo, L.E. 1981. Auditor size and audit quality. Journal of Accounting and Economics, Vol. 3.

Donnelly, P. David, Jeffrey J. Quirin, and David O'Bryan. 2003. Auditor Acceptance of Disfunctional Audit Behavior: An Explonatory Model Using Auditor's Personal Charateristics. Behavior Research In Accounting, Volume 15.

E.Kieso, Donald, Jerry J, Weygandt dan Teery D. Warfield. 2011. Intermediate Accounting, Jakarta: Erlangga.

Eka Purwanda, Maula Ash Shiddieqy.2013. The Influence Of Auditor Personality Characteristics and Disfunctional Behavior To Audit Quality. STAR Study \& Accounting Research. Vol $\mathrm{X}$. 
Gundry, Leanne C. 2006. The Effect Of Time Budget Pressure And Auditor's Personality Type On Reduced Audit Quality Practices. Tesis. University of Otago.

Herrbach, O. 2001. Audit Quality, Auditor Behaviour and the Psychological Contract. European Accounting Review. Vol. 10.

Husna Lina Febrina. 2012. Analisis Pengaruh Karakteristik Personal Auditor Terhadap Penerimaan Auditor Atas Disfungsional Audit Behavior (Studi Empiris Pada Kantor Akuntan Publik di Jawa Tengah dan Yogyakarta). Skripsi. Universitas Diponegoro

Idiah Wahyuni Ratnaningtias. 2014. Pengaruh Time Budget Pressure Terhadap Reduced Audit Quality Dan Under Reporting Of Time : Dampak Budaya Etika Terhadap Kualitas Audit. Skripsi. Universitas Diponegoro.

Imam Wahyudi, Jurica Lucyanda, dan Loekman H. Suhud. 2011. Praktek Penghentian Prematur Atas Prosedur Audit. Media Riset Akuntansi:Vol 1 No. 1.

Indarto, Stefani Lily. 2011. Analisis Faktorfaktor yang Mempengaruhi Penghentian Prematur Atas Prosedur Audit. Dinamika Sosial Ekonomi : Vol 7.

Intan Pujaningrum dan Arifin Sabeni. 2012. Analisis Faktor-faktor yang Mempengaruhi Tingkat Penerimaan Auditor Atas Penyimpangan Perilaku dalam Audit. Diponegoro Journal of Accounting : Vol.1 No. 1

Kaplan, Steven E. 1995. An Examination of Auditors' Reporting Intentions
Upon Discovery of Procedures Prematurly Signed-Off. Auditing : A Journal of Practice and Theory.

Kelley, T. and Margheim, L. 1990. The Impact of Time Budget Pressure, Personality and Leadership Variabels on Dysfunctional Behaviour. Auditing: A Journal of Practice and Theory.

Malone, C.F., and R.W. Roberts. 1996. Faktors Associated with the Incidence of Reduced Audit Quality Behavior. Auditing: A Journal of Practice and Theory 15.

McGuy, C. Wayne Alderman, Alan J Winters. 2002. Auditing. Edisi 5. Jakarta:Erlangga

McNamara, Shaun M. 2008. Time Budget Pressure and Auditor dysfunctional behavior within an occupational stress model. Accountancy Business and Publik Interest. Vol. 7.

Mutiara Puspa Widyowati.2013. Analisis Pengaruh Karakteristik Internal Pada Auditor Eksternal Terhadap Praktik Pengurangan Kualitas Audit. Skripsi. Universitas Jember.

Otley, D.T. and Pierce, B. J. 1996. Audit Time Budget Pressure: Consequences and Antecedents. Accounting, Auditing and Accountability Journal, 9 (1).

Piter Simanjuntak. 2008. Pengaruh Time Budget Pressure Dan Risiko Kesalahan Terhadap Penurunan Kualitas Audit. Tesis. Universitas Diponegoro.

Pricilia Resky Sampetoding. 2014. Hubungan Antara Time Budget Presure, Locus Of Kontrol Dan Komitmen Organisasi Terhadap Perilaku Disfungsional Audit dan 


\section{JURNAL NOMINAL / VOLUME V NOMOR 2 / TAHUN 2016}

Pengaruhnya Pada Kualitas Audit. Skripsi. Universitas Hasanuddin.

Rafela Eriyanti. 2012. Pengaruh Time Budget Pressure Dan Locus of Kontrol Terhadap Praktik Perilaku Penurunan Kualitas Audit (Reduced Audit Quality Behavior). Skripsi. Universitas Pendidikan Indonesia.

Sucahyo, Herningsih. 2001. Penghentian Prematur atas Prosedur Audit : Studi Empiris pada Kantor Akuntan Publik. Tesis. Yogyakarta: Universitas Gajah Mada.

Sugiyono. 2012. Statistika Untuk Penelitian. Cetakan ke-21, Bandung: Alfabeta

Sukrisno Agoes, dan Estralita Trisnawati. 2012. Praktikum Audit: Seri 2. Jakarta: Salemba Empat.

Suryanita Weningtyas, Doddy Setiawan, dan Hanung Triatmoko.2006.
Pengehentian Prematur Atas Prosedur Audit. Padang:Simposium Nasional Akuntansi 9.

Sutrisno Hadi. 2004. Metodologi Research. Jilid 3. Yogyakarta: Andi

Uma Sekaran. 2007. Metodologi Penelitian Untuk Bisnis. Edisi 4. Buku 1. Jakarta: Salemba Empat.

Watkins, A.L., W.Hilison, dan SE Morecroft. 2004. Audit Quality:A Synthesis of Theory and Empirical Evidence. Journal of Accounting Literature.

Yuke Irawati dan Thio Anastasia. 2005. Hubungan Karakteristik Personal Auditor

Terhadap Tingkat Penerimaan Penyimpangan Perilaku dalam Audit. Solo : Simposium Nasional Akuntansi VII 
JURNAL NOMINAL / VOLUME V NOMOR 2 / TAHUN 2016 